\title{
Reducing psychiatric stigma and discrimination: evaluation of educational interventions in UK
} secondary schools

\author{
VANESSA PINFOLD, HILARY TOULMIN, GRAHAM THORNICROFT, \\ PETER HUXLEY, PAUL FARMER and TANYA GRAHAM
}

\begin{abstract}
Background The persistent and disabling nature of psychiatric stigma has led to the establishment of global programmes to challenge the negative stereotypes and discriminatory responses that generate social disability, but these initiatives are rarely evaluated.
\end{abstract}

\begin{abstract}
Aims To assess the effectiveness of an intervention with young people aimed at increasing mental health literacy and challenging negative stereotypes associated with severe mental illness.
\end{abstract}

\section{Method A total of 472 secondary school students attended two mental health awareness workshops and completed pre-and post-questionnaires detailing knowledge, attitudes and behavioural intentions.}

\section{Results Young people use an extensive vocabulary of 270 different words and phrases to describe people with mental health problems: most were derogatory terms. Mean positive attitude scores rose significantly from 1.2 at baseline to 2.8 at I-week follow-up and 2.3 at a 6 -month follow-up. Changes were most marked for female students and those reporting personal contact with people with mental illness.}

\section{Conclusions Shorteducational workshops can produce positive changes in participants' reported attitudes towards people with mental health problems.}

\section{Declaration of interest The study} was funded by an educational grant from Lundbeck UK.
Society has long faced the challenge of breaking down stigma and discrimination associated with mental ill health. Despite the common occurrence of mental health problems, societies continue to hold deeprooted, culturally sensitive, negative beliefs about mental illnesses (Fabrega, 1991; Crisp et al, 2000). Around the world there are programmes in place to reduce psychiatric stigma (World Psychiatric Association, 2000) and a knowledge base to support these initiatives is slowly emerging (Rabkin, 1974; Bhugra, 1989; Haywood \& Bright, 1997; Byrne, 2001). Link (2001) identifies two key principles that result in effective and sustained stigma change: approaches must be multi-faceted and multi-level; and they must address the deeply held attitudes and beliefs that are the fundamental causes of stigma. Psychiatric stigma research evaluating 'what works' in practice, however, is underdeveloped. The aim of this paper is to assess the effectiveness of 'real world' interventions to increase mental health literacy and challenge negative stereotypes associated with mental illness. A pilot project working with young people in UK secondary schools is examined.

\section{METHOD}

\section{Intervention programme}

The main strategies for addressing psychiatric stigma and discrimination focus on protest, contact and education (Corrigan et al, 2001). The research presented in this paper draws upon two of these strategies with young people: contact and education. The study was based in southern England, in the county of Kent, and the workshops were delivered by members of the MidKent Mental Health Awareness group, a partnership initiative involving people with experience of living with mental health problems and people working in the field of mental health. Schools participating in the pilot programme received two 1-h educational interventions within the personal, social, health and education curriculum for year-10 pupils (students aged 14-15 years). A two-phase project was evaluated over four school terms in these schools. Two schools were grammar schools for girls and three were coeducational comprehensives. All participating schools had identified concerns over the emotional well-being of their pupils and sought advice on developing educational sessions to address the issue.

Phase I mental health awareness workshops were delivered by a facilitator who worked in the field of mental health. The first hour-long session concentrated on pupils' understanding of mental health and mental illness, including the viewing of a short video about people living with depression and schizophrenia. The second session concentrated on promoting a positive sense of well-being and challenging the use of stereotypical labels such as 'nutter', 'loony', 'mental' and 'psycho', language known to dominate young people's descriptions of mental illness (Weiss, 1994; Bailey, 1999). A non-medicalised approach was adopted, with emphasis placed on removing the distance between 'us' and 'them' rather than exploring a medical disease paradigm. The lesson plans were designed around a series of group exercises. The workshops were supported by information leaflets produced specifically for young people.

In phase II, sessions were co-facilitated by a person who had personal experiences of living with mental health problems. Phase I lesson plans were used but, in addition, personal experiences were shared sensitively with students through a short talk followed by a question-and-answer session. No control schools were involved in the pilot programme.

\section{The evaluation}

Pupils completed a pre-test questionnaire at the start of the first session and a follow-up assessment 1 week after attending the second session. Pupils in phase I schools also completed a 6-month follow-up assessment. The questionnaires were based on an instrument piloted in the World Psychiatric Association's anti-stigma schools project in Canada (World Psychiatric Association, 2000) and included: four factual statements (e.g. one in four people will develop mental health problems over 
the course of their lives) and five attitude statements (e.g. people with mental health problems are unpredictable), all rated 'agree', 'disagree', 'unsure', and four social distance rating scales rated 'definitely', 'probably', 'probably not', 'definitely not' and 'not known' (e.g. I would be afraid to talk to someone with mental health problems). Social distance scales are used as proxy indicators of planned reported behaviour. The factual statements tested student recall of information provided to them in the workshops. An aggregate attitude score was created by totalling the five individual items. Pre-tests included an open-ended question asking for descriptions of people with mental health problems, and the follow-up surveys asked students to provide assessment ratings for the overall programme. Limited sociodemographic data and a rating to indicate personal experience through knowing someone with mental health problems (termed personal contact) were also collected. The questionnaire was a pilot instrument.

Quantitative data for the study were analysed using the SPSS (version 10) for Windows. Paired $t$-tests compared the differences between baseline and follow-up attitude scores. In this exploratory study we have compared mid-point to baseline and final follow-up to baseline separately when comparing student views over time. Analysis of variance was used to estimate the relationship between general attitude scores and respondent characteristics. Qualitative data were coded using basic content analysis. These data were coded twice by one researcher (V.P.) and once by another member of the research team (H.T.) to identify emergent themes.

\section{RESULTS}

\section{Response rates}

Of the 634 year-10 students identified, 472 students received both mental health awareness workshops and completed baseline and follow-up assessment, providing a $74 \%$ response rate. A 6-month follow-up involved phase I schools with 325 students, of which 236 responded (73\%).

\section{Sample characteristics}

The sample was predominantly female (73\%), 208 students $(44 \%)$ reported that they personally knew someone with generalised mental health problems and 182 students $(39 \%)$ attended a workshop including a personal experience talk. Fiftytwo per cent of the sample attended the coeducational schools and $48 \%$ attended the girls' grammar schools.

\section{The linguistic landscape}

Young people use an extensive vocabulary of terms to describe mental ill health. As shown in Table 1 , the sample applied 270 different words or short phrases to describe a person with a mental health problem. Although the majority were derogatory terms, a quarter of pupils applied only sensitive descriptions focusing upon people's emotions and positive characteristics:

\begin{abstract}
'I would call them different but I wouldn't mind it.I would just feel strange, I definitely wouldn't say anything to hurt them or make them feel worse than they already are.'
\end{abstract}

'I wouldn't call them any thing because it can mean all sorts of different problems.'

'Mental illnesses are problems that they might not think they can overcome.'

Few mental health descriptions related to emotional well-being, although young people do relate both mental health and mental illness with emotion states. When students were asked in the 6-month follow-up what they most remembered about the sessions, $37 \%$ noted the exercises that addressed language used to describe mental health problems, compared with $15 \%$ who remembered the video that was shown.

Table I Student descriptions' of people with mental health problems $(n=400)$

\begin{tabular}{|c|c|c|c|c|c|}
\hline $\begin{array}{l}\text { Emotions } \\
\text { (3I terms, II\%) }\end{array}$ & $\begin{array}{l}\text { Characteristics } \\
\text { (75 terms, 28\%) }\end{array}$ & $\begin{array}{l}\text { Labels } \\
\text { (II5 terms, 42\%) }\end{array}$ & $\begin{array}{l}\text { Suggested causes } \\
\text { (22 terms, } 8 \% \text { ) }\end{array}$ & $\begin{array}{l}\text { Medical terms } \\
\text { (15 terms, 6\%) }\end{array}$ & $\begin{array}{l}\text { Sensitive descriptions } \\
\text { (12 terms, } 4 \% \text { ) }\end{array}$ \\
\hline Confused (29) & Unstable (19) & Mental (68) & Under pressure (6) & Mentally ill (55) & Misunderstood (7) \\
\hline Depressed (23) & Different (22) & Psycho (52) & Brain damage (6) & Depression (13) & Normal (4) \\
\hline Unhappy (17) & Isolated (II) & Nutter (52) & & Schizophrenia (7) & No different (4) \\
\hline
\end{tabular}

I. The words in the table are those most frequently suggested by young people and the numbers in parentheses denote frequency of response.

Table 2 Student attitude changes towards people with mental health problems

\begin{tabular}{|c|c|c|c|}
\hline Attitude statement ${ }^{1}$ & $\begin{array}{c}\text { Baseline } \\
\text { positive ratings } \\
(n=469)\end{array}$ & $\begin{array}{l}\text { One-week follow-up } \\
\text { positive ratings } \\
(n=466)\end{array}$ & $\begin{array}{l}\text { Six-month follow-up } \\
\text { positive ratings } \\
(n=207)\end{array}$ \\
\hline (a) People with mental health problems are difficult to talk to & $182(39 \%)$ & $294(63 \%)^{2}$ & $108(55 \%)^{3}$ \\
\hline (b) People with mental health problems are likely to be violent & $172(37 \%)$ & $324(70 \%)^{2}$ & $110(56 \%)^{3}$ \\
\hline (c) People can recover from mental health problems & $323(68 \%)$ & $4 I I(87 \%)^{2}$ & $165(83 \%)^{3}$ \\
\hline (d) People with mental health problems are weak and only have themselves to blame & $418(89 \%)$ & $428(92 \%)$ & $181(92 \%)$ \\
\hline (e) People with mental health problems are unpredictable & $50(11 \%)$ & $157(34 \%)^{2}$ & $42(22 \%)^{3}$ \\
\hline
\end{tabular}

I. Students were regarded as having a 'positive' opinion if they agreed with statement (c) and disagreed with the remaining four statements.

2. Attitude statements significantly more positive at I-week follow-up compared with baseline $(P<0.000 \mathrm{I})$.

3. Attitude statements for students returning all three data-sets are significantly more positive at 6 -month follow-up compared with baseline $(P<0.00 \mathrm{I})$. 


\section{Changes in student views}

Student responses to five attitude statements are shown in Table 2 . When composite attitude scores were compared (range -5 to +5 ), mean scores rose from $1.2($ s.d. $=1.8)$ at baseline to $2.8($ s.d. $=1.9)$ at the 1-week follow-up $(t=-16.4$, $P<0.0001)$. At the 6-month follow-up the mean score had fallen to 2.3 (s.d.=1.9), although this was still significantly higher than the score at baseline $(t=-8.5$, $P<0.0001)$. Analysis of variance was used to estimate the relationship between composite attitude scores (dependent variable) and sample characteristics. Attending grammar school and personal contact were associated independently with a higher baseline attitude score, but this model was poor at predicting individual baseline scores $\left(R^{2}=7 \%\right)$. Baseline attitude score, being female, personal contact and attending grammar school were associated independently with a positive change in attitude scores between baseline and the 1-week follow-up $\left(R^{2}=31 \%\right)$. At the 6month follow-up, baseline attitude scores and personal contact were associated independently with a positive change $\left(R^{2}=11 \%\right)$. Seventy-three per cent of students self-rated their attitudes as more positive towards people with mental health problems immediately after attending the workshop sessions and $61 \%$ retained a positive self-rating at 6-month follow-up.

\section{Changes in social distance ratings}

The cumulative proportion of students expressing no social distance across four items changed marginally over time: baseline, 32 students $(8 \%, n=421)$; 1-week follow-up, 58 students $(13 \%, n=434) ; 6$ month follow-up, 24 students (11\%, $n=207)$. Across individual social distance items, reported social distance did not change significantly in the post-intervention follow-ups except for students reporting that they were less afraid to talk to someone with a mental health problem at the 1-week follow-up (32\%) than at baseline (22\%): $t=5.98$, $P<0.0001$. Analysis of variance identifies that baseline social distance scores and the inclusion of a personal experience talk within the programme are two variables associated independently with a reduction in social distance at the 1-week follow-up $\left(R^{2}=34 \%\right)$. The impact of a personal experience talk was not assessed at the 6month follow-up because phase II schools were not re-assessed at 6 months.

\section{Impact on mental health literacy}

At baseline only six students (1\%) provided correct ratings for all four factual statements. Significant changes in these ratings were recorded at the 1 -week postintervention follow-up, as shown in Table 3, but the 6-month follow-up data indicated that factual recall changes may not be long-lasting. At the 1-week followup, $24 \%$ of students provided correct ratings for all four factual statements, but this proportion fell to $6 \%$ after 6 months.

\section{Effect of individual characteristics on student views}

To explore the impact of education on public attitudes, we compared the responses from coeducation female students $(n=118)$ and students at the girls' grammar schools $(n=221)$. The grammar school students reported significantly higher (and thus more-positive) factual and attitude scores at all three data collection points. Mean attitude scores for females in the coeducational schools increased from 1.0 to 2.6 between baseline and the 1-week followup, and for the girls' grammar school students the increase was similar (mean
1.7-3.4). The difference between coeducation and girls' grammar school increases in factual recall scores were more marked: coeducation, from -0.4 to 1.3 ; girls' grammar school, from 0.4 to 2.8 .

To explore the relationship between gender and opinions of people with mental health problems, a comparison between male $(n=122)$ and female $(n=118)$ responses in coeducation schools was carried out. At baseline there were no significant differences between male and female coeducation factual, attitude or social distance rating scores, but a higher proportion of female students in coeducational schools reported different views at follow-up compared with their male colleagues. In particular, female coeducation students were more likely than male colleagues to rate that people with mental health problems were not difficult to talk to at the 1week follow-up (61\% females compared with $48 \%$ males, $\left.\chi^{2}=4.34, P=0.03\right)$ and 6-month follow-up ( $58 \% v$. 39\%, $\chi^{2}=4.4$, $P=0.03$ ), not to blame for their mental health difficulties (1-week follow-up: 91\% v. $77 \%, \chi^{2}=9.2, P=0.002$; 6-month follow-up: $94 \%$ v. $83 \%, \chi^{2}=3.2, P=0.05$ ) and would not be upset or embarrassed to be in the same class as someone with mental health problems (1-week follow-up: $61 \%$ v. $43 \%, \chi^{2}=4.0, P=0.04 ; 6$-month follow-up: $67 \% v .49 \%, \chi^{2}=4.0, P=0.04$ ).

\section{DISCUSSION}

\section{Educational interventions and stigma change}

Consistent with findings from short programme interventions with adult populations (Wolff et al, 1996; Holmes et al, 1999), educational workshops with young people can have a small but positive impact on students' views of people with mental health problems. When students were asked

Table 3 Changes in student recall of factual information on mental health problems

\begin{tabular}{|c|c|c|c|}
\hline Statement & $\begin{array}{l}\text { Correct ratings at } \\
\text { baseline } \\
(n=468)\end{array}$ & $\begin{array}{l}\text { Correct ratings at } \\
\text { I-week follow-up } \\
\quad(n=468)\end{array}$ & $\begin{array}{l}\text { Correct ratings at } \\
\text { 6-month follow-up } \\
\quad(n=207)\end{array}$ \\
\hline Mental health problems are caused by stress & $160(34 \%)$ & $294(64 \%)^{1}$ & 75 (38\%) \\
\hline People with schizophrenia have a split personality & $46(10 \%)$ & $243(53 \%)$ & $56(29 \%)^{2}$ \\
\hline There is a stigma attached to mental health problems & $198(42 \%)$ & $305(65 \%)^{1}$ & $118(60 \%)^{2}$ \\
\hline One in four people will develop mental health problems over the course of their lives & $164(35 \%)$ & $386(82 \%)^{\prime}$ & $|2|(6 \mid \%)^{2}$ \\
\hline
\end{tabular}

I. Statements significantly more positive at I-week follow-up compared with baseline $(P<0.0001)$.

2. Statements for students returning all three data-sets are significantly more positive at 6 -month follow-up compared with baseline $(P<0.05)$. 
in the workshops to find less-stigmatising descriptions for a person's problems, the majority focused on people's feelings rather than labels: sad, dazed, lonely, scared, normal. Although the measured impact of the intervention had weakened by the long-term follow-up, overall there were small but positive shifts in student understanding of mental health and mental illness. This was particularly true for students rating personal contact with someone living with mental health problems and for female students in both types of school.

Unsurprisingly, some popular stereotypes surrounding mental illness are easier to challenge than others because interventions must work against powerful providers of 'misinformation' such as the media. Studies highlight how, through films (Wahl \& Lefkowits, 1989), newspaper reports (Philo, 1996) and television programmes (Wilson et al, 2000), people with mental health problems are represented in stereotypical roles and a pejorative language against difference is normalised through 'crazy', 'out of control', 'loony' characters. Overall, the workshops did not have an impact on the 'them' and 'us' phenomenon because few changes in social distance ratings were reported. It will take more than two short educational workshops to address young people's deep-rooted beliefs and fears about interacting with people with severe mental illness. However, introducing the subject of mental illness alongside a personal, social, health and education teaching programme that focused upon other important social and health issues, such as friendship and bullying, healthy eating and contraception, should ensure that mental health problems are recognised as a central health concern for young people to understand and self-manage.

\section{Promoting personal contact}

The study assessed the importance of experiential learning as a teaching strategy to reduce psychiatric stigma and discrimination. This was, in part, a response to student demands to improve the sessions by introducing a speaker to discuss personal experiences of living with depression or schizophrenia. Guarding against the use of tokenism, the programme responded by training co-facilitators for phase II of the study and the inclusion of personal experience talks did have an impact on social distance scores. Personal contact was particularly important in

\section{CLINICAL IMPLICATIONS}

- Mental health educational sessions with young people are a useful approach for challenging the development of stereotypical attitudes towards people with mental health problems.

- Our findings suggest that there are differences in how young men and women connect to, and learn about, mental health and mental illness. Teaching sessions should adopt methods that recognise these differences.

- Thorough evaluation of school mental health awareness programmes is needed to ensure that limited health promotion resources are effectively targeted.

\section{LIMITATIONS}

Pre- and post-study design without a control group.

Potential social desirability bias in attitude assessments.

- The written views and expressed attitudes of young people may not translate into any enduring behavioural change.

VANESSA PINFOLD, PhD, HILARY TOULMIN, MA, GRAHAM THORNICROFT, FRCPsych, PETER HUXLEY, PhD, Health Service Research Department, Institute of Psychiatry, London; PAUL FARMER, BA, Rethink Severe Mental IIIness, London; TANYA GRAHAM, MSc, Health Service Research Department, Institute of Psychiatry, London

Correspondence: Dr Vanessa Pinfold, Section of Community Psychiatry (PRiSM), Health Service Research Department, Institute of Psychiatry, De Crespigny Park, Denmark Hill, London SE5 8AF, UK. e-mail:v.pinfold@iop.kcl.ac.uk

(First received 9 July 2002, final revision 19 November 2002, accepted 3 December 2002)

affecting attitude scores, suggesting that students who know someone with mental health problems learnt more from the sessions than those who did not associate the subject area with a personal contact. Anti-discrimination work undoubtedly benefits from collaborative partnerships in the planning and delivery of mental health education sessions, and future studies should develop the co-facilitation strategy. The empowerment of mental health consumers may be promoted through mental health education projects, and thus consumer involvement may have a positive impact on both the learning experiences of young people and the mental health of consumer facilitators. Further research is needed to establish a best-practice teaching model for mental health, comparing teacher-led and 'expert'-led interventions.

\section{Study limitations}

The study had several limiting factors. Working within pragmatic constraints, the project team delivered a short educational intervention that was evaluated using a brief self-report survey. It is important to acknowledge the limitations of pen-andpaper assessments for capturing attitude and knowledge changes, behavioural responses and the impact of potential social desirability bias. The study was a small uncontrolled intervention and thus the findings are weakened by the lack of any control group. Although the measured changes in student opinions are likely to be the result of the workshop interventions, this conclusion may only be inferred. Response rates were moderate.

\section{The agenda for mental health education in schools}

The strains placed on the emotional wellbeing of young people in modern society have been well documented (Mental Health Foundation, 1999) and the rate of suicide among young people, particularly young men, is a growing concern. Despite the 
prevalence of mental illness, the majority of young people experiencing emotional problems do not consult their general practitioner (Potts et al, 2001). Young people, therefore, have been the focus of several mental health awareness pilot schemes, including a community mental health programme in Rawalpindi, Pakistan (Rahman et al, 1998), and the 'Mindmatters' programme in Australia (Wyn et al, 2000). A UK population formally uneducated on issues related to mental health and mental illness is sustained by an education system that does not include emotional health as a core part of the national curriculum, not even in the personal, social, health and education programme. Ideally, a short educational programme addressing psychiatric stigma and discrimination should be part of a whole-school strategy supporting the emotional well-being of young people and school staff. Stigmareducing interventions would be part of a compulsory mental health promotion strategy that extends through the school curriculum year on year, addressing social values, health and social well-being and the development of social skills to promote socially responsible behaviour. The introduction of compulsory 'citizenship classes' in the curriculum in the UK from September 2002 may assist this important agenda.

\section{ACKNOWLEDGEMENTS}

The research team are grateful to all the young people who completed the questionnaires and we are particularly grateful to Jackie Brewer, coordinator at Maidstone MIND, who facilitated the workshops Thanks are extended also to Morven Leese for her statistical advice and to the two anonymous reviewers.

\section{REFERENCES}

Bailey, S. (1999) Young people, mental illness and stigmatisation. Psychiatric Bulletin, 23, 107-110.

Bhugra, D. (1989) Attitudes towards mental illness. A review of the literature. Acta Psychiatrica Scandinavica, $80,1-12$.

Byrne, P. (200I) Psychiatric stigma. British Journal of Psychiatry, 178, 281-284.

Corrigan, P., River, P., Lundin, R., et al (200I) Three strategies for changing attributions about severe mental illness. Schizophrenia Bulletin, 27, 187-195

Crisp, A. H., Gelder, M. G., Rix, S., et al (2000) Stigmatisation of people with mental illnesses. British Journal of Psychiatry, 177, 4-7.

Fabrega, H. (1991) Psychiatric stigma in non-Western societies. Comprehensive Psychiatry, 32, 534-55I.

Hayward, P. \& Bright, J. A. (1997) Stigma and mental illness: a review and critique. Journal of Mental Health, $\mathbf{6}$, 435-454.

Holmes, P., Corrigan, P., Williams, P., et al (1999) Changing attitudes about schizophrenia. Schizophrenia Bulletin, 25, 447-456.

Link, B. (200I) Stigma: many mechanisms require multifaceted responses. Epidemiologia e Psichiatria Sociale, 10, 8-11.
Mental Health Foundation (1999) Bright Futures: Promoting Children and Young People's Mental Health. London: Mental Health Foundation.

Potts, Y., Gillies, M. L. \& Wood, S. F. (200I) Lack of mental well-being in 15 year-olds: an undisclosed iceberg? Family Practice, 18, 95-100.

Philo, G. (1996) Media and Mental Illness. London: Longman.

Rabkin, J. (1974) Public attitudes toward mental illness: a review of the literature. Schizophrenia Bulletin, 10, 9-23.

Rahman, A., Mubbashar, M. H., Gater, R., et al (1998) Randomised trial of impact of school mentalhealth programme in rural Rawalpindi, Pakistan. Lancet, 352, $1022-1025$

Wahl, O. F. \& Lefkowits, J. Y. (1989) Impact of a television film on attitudes toward mental illness. American Journal of Community Psychology, 17, 521-528.

Weiss, M. (1994) Children's attitude towards the mentally ill: an eight year longitudinal follow-up. Psychological Reports, 74, 5I-56.

Wilson, C., Nairn, R., Coverdale, J., et al (2000) How mental illness is portrayed in children's television. A prospective study. British Journal of Psychiatry, 176, 440-443.

Wolff, G., Pathare, S., Craig, T., et al (1996) Public education for community care. A new approach. British Journal of Psychiatry, 168, 44I-447.

World Psychiatric Association (2000) The WPA Programme to Reduce Stigma and Discrimination because of Schizophrenia, Vols I-5. Geneva: WPA.

Wyn, J., Cahill H, Holdsworth, R., et al (2000) Mindmatters, a whole school approach promotin mental health and wellbeing. Australian and New Zealand Journal of Psychiatry, 34, 594-601. 